\title{
Chronic obstructive pulmonary disease: The importance of exercise
}

\author{
Dr Norman L Jones MD \\ McMaster University Health Sciences Centre \\ Hamilton, Ontario
}

\section{Why do I find it difficult to exercise?}

Patients with chronic obstructive pulmonary disease (COPD - chronic bronchitis, emphysema, asthma) are often limited in their capacity to exercise, mainly because they experience shortness of breath or muscle fatigue. The reasons for shortness of breath are dealt with in another patient page (Can Respir J 2000;7(1):35-36), and include narrowing of the airways, poor lung function leading to falls in the amount of oxygen carried in the blood and weak muscles for breathing. Easy fatiguability may be because of muscle weakness or changes in muscle function, related to inactivity and ageing. Other less common factors include heart problems associated with COPD, and other coexisting health problems, such as anemia and arthritis.

\section{How severe is my limitation?}

The severity of exercise limitation is commonly judged by your ability to engage in daily activity, and graded as follows:

0 - able to walk as far as you like on level ground, climb two flights of stairs without stopping.

1 - unable to hurry, walk up hills or two flights of stairs without stopping.

2 - unable to keep up with someone of your own age at an ordinary pace on level ground.

3 - unable to walk at your own pace without stopping.

4 - cannot walk more than a block at a slow pace.

5 - confined to the house.

\section{How do I find out what is limiting me?}

The first thing to do is to discuss your limitations with your family doctor and find out whether simple tests of lung function and exercise might help. At the simplest level, spirometry can assess whether airway narrowing is the most important cause; the measurement of the one second forced expired volume (FEV1) is expressed in litres or as a percentage of the value predicted for a healthy person of your age, sex and height (FEV1\% predicted). Usually FEV 1 is less than 1.5 litres or $30 \%$ predicted in patients with grade 3 or greater limitation. As mentioned in the first patient page (COPD Number 1), we recommend that you find out your FEV1. Formal exercise testing may be available at your local hospital; this has the potential of measuring the limitation and identifying all the contributing factors - including limited capacity to breathe, fall in blood oxygen, weakness and poor muscle function. 


\section{What can I do about my limitation?}

Maintaining your activity is extremely important, for many obvious reasons. There are four main approaches:

1. Effective treatment of airway narrowing. This may include inhalers and tablets, and their effectiveness may be judged by improvements in your FEV1.

2. Oxygen treatment. Oxygen may be administered by small, lightweight, portable tanks, to prevent your blood oxygen from falling. The need for this treatment is shown by an exercise test with an instrument that detects oxygen through the skin (pulse oximeter), to show first, that there is the need for oxygen in exercise; and second, that the giving of oxygen improves exercise capacity.

3. Exercise programs. Many patients gain benefit from group activity programs that incorporate endurance activity (walking, swimming, treadmill or cycle exercise) and muscle strengthening (weights, springs), or by similar activity at home with simple equipment (corridor or mall walking, weight lifting, working against elastic bands, etc). You will need advice from your doctor; programs are often provided by the local Lung Association ('Better Breathing Club'), the hospital chest clinic and physiotherapy department. A form of muscle exercise that many patients find helpful is to work out muscles against wide elastic bands that have a graduated resistance (Thera-Band System, The Hygenic Corp, Akron, Ohio); they are available at most large pharmacies, are not costly, and come with instructions.

However limited you feel, you should work at this aspect of your care, because 'if you don't use it, you'll loose it'. Benefits include greater confidence and control, less fatigue and shortness of breath, and stronger respiratory and limb muscles.

4. Energy conservation. All activities require you to expend energy, but by adopting certain techniques, you may be able to cut the amount of energy required for a given activity. Referral to a rehabilitation program will allow you to be assessed, an individual program can be drawn up and you will be able to obtain advice on these techniques.

5. A well balanced diet is necessary to prevent weight gain, maintain protein intake for muscle strength and provide natural carbohydrates as energy sources.

\section{Where can I get more information?}

There are many organizations that provide help and advice. Foremost is The Lung Association, which has an attractive Internet Web Site (www.lung.ca) and many local affiliates; they publish "Living well with COPD", which is available from local Lung Associations. Many local associations run a 'Better Breathing' or 'Breathe Easy' Club, which is professionally run and includes exercise components. If you wish to hear about how other patients are coping with COPD and exercising, their experiences have been collected in an amateur video available from Ron Petersen ("Maintaining your health with lung disease”, Ron Peterson, 5353 Walsh \#1B, St Louis, MO, 63109 USA).

This information should not be used as a substitute for the medical care and advice of your physician. There may be variations in treatment that your physician may recommend based on individual facts and circumstances. This information may be reproduced without permission and shared with patients and their families. 


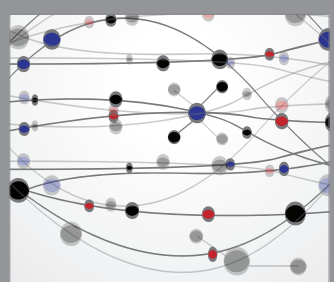

The Scientific World Journal
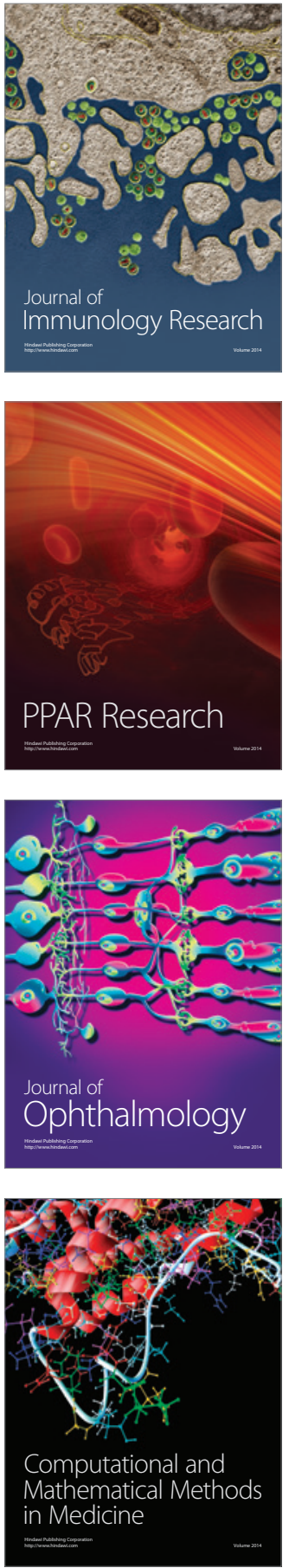

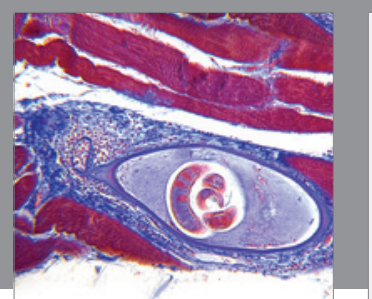

Gastroenterology Research and Practice

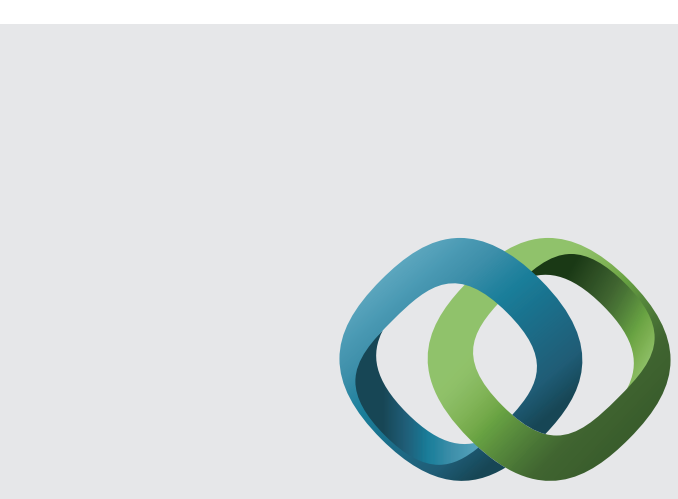

\section{Hindawi}

Submit your manuscripts at

http://www.hindawi.com
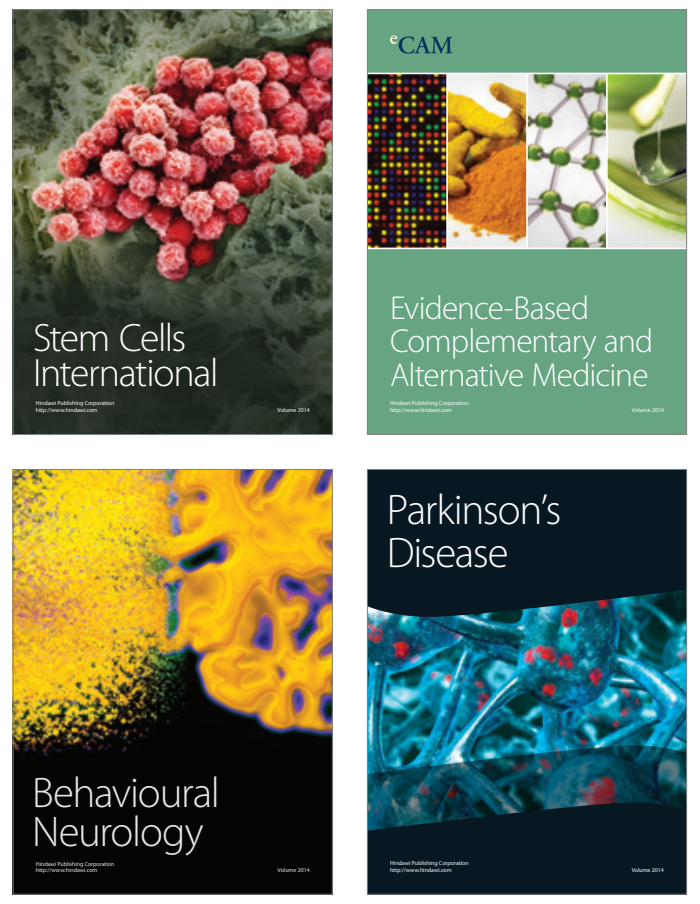


Disease Markers
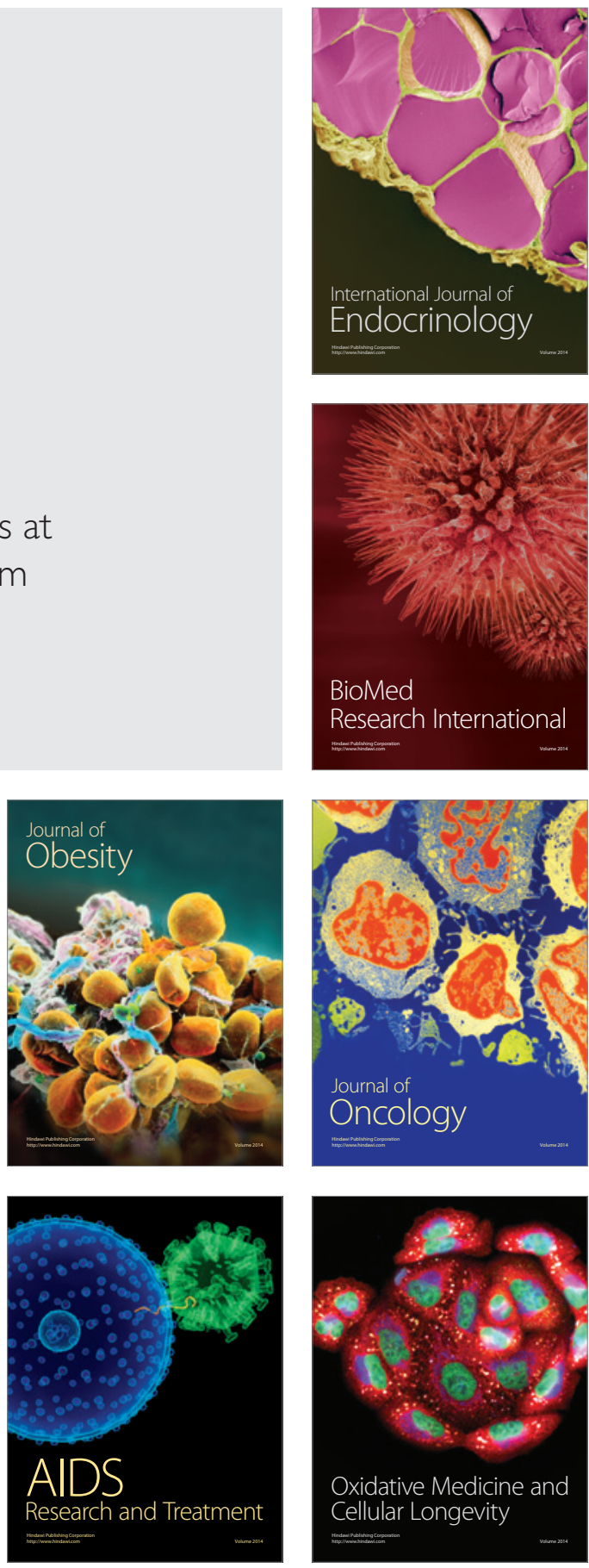